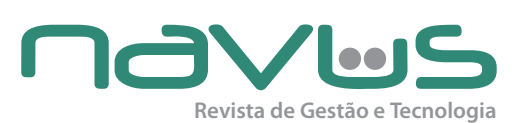

\title{
Os empreendedores de vinhos de altitude do planalto catarinense
}

\author{
Nubia Alves de Carvalho Ferreira, Carlos Luiz Nunes Júnior e \\ Álvaro Guillermo Rojas Lezana
}

\section{RESUMO}

O objetivo desse estudo é analisar e classificar os empreendedores de vinhos de altitude do Planalto Catarinense, por meio da utilização da tipologia de Westhead e Wright (1998). Esses autores apontam três tipos - o noviço/iniciante, o serial e o de portfólio. Para tanto, analisa quais são as características empreendedoras utilizadas. Verifica ainda se o fato de possuírem experiência em outros setores colabora para a consolidação dessa nova atividade. Trata-se de uma abordagem qualitativa, sendo a pesquisa do tipo exploratória que se configura como um estudo de caso. Os dados foram coletados por meio de pesquisa a sites, revistas, documentos e pessoas envolvidas no processo de formação e gestão dos empreendimentos em vinhos de altitude e, sobretudo, por meio de entrevistas semiestruturadas com os empreendedores. Os resultados obtidos demonstram a tipologia portfólio, evidenciam as habilidades como a característica preponderante desses empreendedores e confirmam outros trabalhos e cases pesquisados e apresentados na literatura. Ressalva-se a necessidade de novas pesquisas, em maior profundidade e número de entrevistados.

Palavras-Chave: Vinhos de altitude. Empreendedores. Portfólio.

\section{RESUMEN}

El objetivo de este estudio es analizar y clasificar los productores de vino de altura de la Región Serrana de SC, por medio de la utilización de la topología de Westhead y Wright (1988). Estos autores apuntan 3 tipos - el novato, el inicial y el serial o de cartera. Para tal, analiza cuales son las técnicas utilizadas por los productores. Verifica aun si por el hecho de poseer experiencia en otros sectores esto colaboraría para la consolidación de esta nueva actividad. Se trata de un abordaje cualitativo, siendo la pesquisa de tipo exploratoria, configurándose como un estudio de caso. Los datos fueron colectados por medio de pesquisas en sitios, revistas, documentos y personas comprometidas con el proceso de formación y gestión de los productores de vino de altitud y sobretodo, por medio de entrevistas semi-estructuradas hechas a los propios productores. Los resultados obtenidos demuestran la tipología de cartera, evidencia las habilidades como la característica predominante de estos productores y confirman otros trabajos y casos pesquisados y presentados en literaturas. Se reitera la necesidad de nuevas pesquisas, con mayor profundidad y mayor numero de participantes entrevistados.

\section{Palabras clave: Vinos de altitud. Productores. Cartera}




\section{INTRODUÇÃO}

A definição do empreendedorismo como objeto de estudo não é consenso entre os investigadores, e é também fracionada conforme afirmam Ucbasaran, Westhead e Wright (2001). Também não há consenso quanto à forma de investigação do assunto. O que é uníssono na literatura, iniciandose por Schumpeter é quanto ao perfil do empreendedor, a criação de uma empresa, o estudo da nova organização e a influência do meio ambiente no empreendedorismo e na mortalidade das jovens empresas.

Empreendedores são considerados os responsáveis pela criação e condução dos empreendimentos. Schumpeter (1982) afirma que o empreendedor seria o responsável pela criação de novos negócios, mas que também pode inovar em empresas existentes. Inovar, para esse autor, é condição necessária para a existência do empreendedor.

Para Brollo (2006, p.19) “o empreendedor é, pois, o indivíduo capaz de se rebelar contra hábitos estabelecidos e métodos de produção tradicionais". Para Schumpeter (1982) é a partir da emergência do empreendedor e de novas formas produtivas que ocorre o desenvolvimento econômico. 0 empreendedor, para Schumpeter (1982), cria novas combinações, que seriam de cinco tipos: um novo bem, um novo mercado, um novo método, novas fontes de matéria-prima e uma nova indústria.

Da mesma forma, Baron e Shane (2007) expõem que empreendedorismo é a interseção entre oportunidades valiosas e indivíduos empreendedores. A identificação de oportunidades é considerada central para o surgimento de novos negócios (BARON; SHANE, 2007; GARTNER, SHANE, 1995; BYGRAVE, HOFER, 1991; ARDICHVILI et al., 2003)

Segundo Shumpeter (1982) o indivíduo empreendedor deve possuir qualidades diferenciadas. Essa afirmação gerou controvérsias e debates, surgindo o questionamento: afinal, quem é o empreendedor? Baron e Shane (2007) afirmam que até recentemente o estudo do processo empreendedor era controverso e se dividia entre focar o indivíduo empreendedor (com seus comportamentos habilidades, motivações) ou no contexto em que esse empreendedor atuava (condições sociais, econômicas). Para esses autores, no entanto, essa questão é irrelevante.

Gartner (1989), Baron e Shane (2007) destacam a abordagem comportamental, mas entendem o empreendedorismo como um processo e que se modifica ao longo do tempo, e não um evento único. 0 entendimento do empreendedorismo como um processo permite apontar os diversos fatores que o afetam. São os fatores relativos aos empreendedores - os indivíduos; outros são os fatores relacionados com outras pessoas envolvidas - clientes, sócios e, ainda, os fatores afeitos à sociedade, como as regulamentações governamentais, por exemplo, que são explicitados como as categorias que desempenham destacado papel em cada fase do processo empreendedor.

Destaca-se na literatura também a discussão sobre tipos de empreendedores. Da mesma forma como não há consenso quanto ao conceito de empreendedorismo, o mesmo ocorre quanto a quem é o empreendedor. Estudos apontam a 
existência de diferentes tipos (BIRLEY; WESTHEAD, 1993; WESTHEAD; WRIGHT, 1998). Esses últimos autores analisam $\mathrm{e}$ apontam três tipos: o empreendedor novato, o serial e o de portfólio, e afirmam que as características e motivações diferem entre os três tipos.

0 empreendedor novato é aquele também chamado de principiante, em contraste aos empreendedores dos tipos serial e de portfólio, agrupados na categoria empreendedor habitual.

A região de São Joaquim, no Planalto Catarinense, recebeu no final dos anos 90 e início dos anos 2000, investimentos de empreendedores interessados na produção de vinhos finos de altitude. 0 objetivo desse trabalho foi analisar e classificar os empreendedores de vinho de altitude do Planalto Catarinense, à luz da tipologia de empreendedores de Westhead e Wright (1998) e investigar quais as características empreendedoras utilizadas para o início do novo negócio. Ao se pesquisar os empreendedores dessa nova atividade produtiva constata-se que são, em sua maioria, empresários oriundos de outras áreas de negócios que ingressam nesse novo negócio e utilizam características empreendedoras para iniciar, lançar e consolidar esse negócio.

Justifica-se este trabalho por permitir conhecer esses empreendedores e suas características, com a utilização de uma tipologia específica e também, demonstrar a evolução da atividade e as ações realizadas pela associação criada para a defesa dos interesses desses empreendedores. Quanto à metodologia, a abordagem é qualitativa, sendo a pesquisa exploratória com base bibliográfica, e entrevistas semiestruturadas com responsáveis pelas vinícolas, pesquisadores e diretores dessa associação. 0 artigo está dividido em seis partes, sendo a primeira esta introdução. A segunda seção aborda a metodologia utilizada. A terceira seção trata dos conceitos relacionados às características empreendedoras, com foco nas habilidades e conhecimentos e os tipos de empreendedores. A seção seguinte apresenta a atividade analisada - a produção de vinhos finos de altitude e alguns dos empreendedores dessa nova atividade. A análise e classificação desses empreendedores é a quinta seção. As considerações são apresentadas na seção seguinte, bem como as referências.

\section{METODOLOGIA}

Considera-se a metodologia como a maneira global de análise do processo de pesquisa (COLLINS; HUSSEY, 2005). Segundo esses autores, o paradigma adotado tem implicação direta para com a metodologia que será utilizada. Nesse trabalho, o paradigma de pesquisa adotado é o qualitativo, também denominado fenomenológico. Para Godói; Balsini (2006 apud Merrian, 2002) a pesquisa qualitativa é um conceito "guarda-chuva" que abrange diferentes formas de pesquisa e que permite a compreensão e explicação de fenômenos sociais, com menor distanciamento do ambiente desses acontecimentos.

A pesquisa qualitativa possui vários métodos, sendo um deles o de estudo de caso. Para Collins e Hussey (2005) o método do estudo de caso é um estudo extensivo de uma única situação ou fenômeno. Para que esse estudo ocorra, é necessário obter, 
reunir e analisar informações sobre essa unidade de análise, durante um determinado período. Estudos de caso são descritos como pesquisa exploratória, pois se propõem a compreender os agentes envolvidos.

Nesse sentido, Diehl e Tatim (2004) afirmam que a pesquisa exploratória proporciona aproximação com o problema, e envolve pesquisa bibliográfica e a realização de entrevistas com indivíduos envolvidos com o assunto pesquisado. Para a realização desse trabalho, foram realizadas pesquisas em sites, revistas, jornais, livros e periódicos de modo a fundamentar teoricamente a pesquisa. Na busca da compreensão do fenômeno analisado, foram realizadas entrevistas com os empreendedores, presidente da Associação Catarinense dos Produtores de Vinhos Finos de Altitude (ACAVITIS), com visitas às vinícolas, lojas especializadas, responsáveis, gerentes e funcionários das vinícolas.

\section{TIPOS DE EMPREENDEDORES E CARACTERÍSTICAS EMPREENDEDORAS}

Para Westhead e Birley (1994) o fenômeno do empreendedorismo é algo complexo e que não se permite reduzir. Assim, se o negócio (empresa) for a única unidade de análise, corre-se o risco de que o fenômeno empreender seja subestimado. Nesse sentido, a pessoa do empreendedor deve ser considerada.

Quanto à existência de um empreendimento Carter et al (1996) estabelece uma distinção entre empreendedor nascente, aquele que aspira iniciar um negócio, em oposição ao empreendedor já estabelecido.

Para Westhead e Wright (1998) as situações de empreendedorismos podem se dar de diferentes formas: fundação inicial de um único negócio, compra e herança, ou empreendimentos múltiplos.

De forma análoga, os próprios empreendedores não podem ser considerados homogêneos, sendo que em levantamento realizado por esses autores foram identificados os seguintes tipos: Empreendedores noviços/iniciantes são aqueles que não têm experiência prévia em nenhuma das situações de empreendedorismo apresentadas quando passam a empreender (UCBASARAN; WESTHEAD; WRIGHT, 2001).

Já os empreendedores com alguma experiência são chamados por Westhead e Birley (1993) de habituais, conceituandoos como aqueles fundadores que já tenham estabelecido pelo menos um negócio anteriormente ao que se inicia. Hall (1995) mantém o conceito de empreendedor habitual e o divide em serial e de portfólio. Para esse autor, o primeiro seria aquele que possui um negócio após o outro, mas efetivamente, apenas, um de cada vez. Sendo que o negócio prévio pode ter sido vendido, fechado ou de alguma forma, encerrado por vias legais. Empreendedor de portfólio, para Hall (1995), é aquele que é proprietário de mais de um negócio ao mesmo tempo.

Hyytinen e Ilmakunnas (2007) em uma pesquisa sobre as aspirações para empreender, ampliaram suas bases de pesquisa entrevistando não somente empreendedores já estabelecidos como também, empregados de empresas. Revelam que os últimos quando possuidores de experiência passada como empreendedores mais provavelmente terão aspirações para iniciar novos empreendimentos. 
Esses, para as autoras, seriam empreendedores seriais. E, como consequências, atribuem que parte do processo de turn-over das empresas se dá pela entrada e saída das pessoas, repetidamente, em projetos pessoais de empreendedorismo.

Westhead e Wright (1998) estabelecem conceitos para os tipos de empreendedores habituais mantendo as possíveis situações de empreendimentos citadas acima, na forma: empreendedores seriais são aqueles que vendem seus negócios originais e, posteriormente, estabelecem, herdam e/ou compram outro negócio. E, empreendedores portfólio são como aqueles que mantêm seus negócios originais e estabelecem, herdam e/ ou compram outro negócio.

Ucbasaran, Westhead, Wright (2001) e Westhead e Wright (1998), em estudo empírico realizado com empreendedores, estabelecem características comportamentais distintas para os tipos empreendedores. Ainda que enfatizem que não foram encontradas evidências sobre diferença de desempenho nos negócios, de acordo com o tipo de empreendedor.

Tanto os empreendedores de portfólio, como os seriais, buscam uma maior quantidade de fonte de informação para estabelecer um negócio do que os empreendedores noviços. E os primeiros usam as redes sociais estabelecidas de suas experiências de negócios anteriores para levantar informações.

Para os autores, os empreendedores seriais tendem a se ater a ideia de níveis de crescimento mais controlados dos negócios, enquanto os de portfólio buscam oportunidades com maior possibilidade de crescimento. Os empreendedores seriais têm no conhecimento técnico a sua maior força.

Os empreendedores seriais manifestam uma maior cautela no estabelecimento de novos negócios, podendo ser uma barreira para o estabelecimento de empreendimentos mais inovadores. Também apresentam uma maior tendência para repetir um negócio bem-sucedido passado do que mudar o mercado de atuação em sua próxima iniciativa. Assim os empreendedores seriais tendem a estabelecer negócios menos sofisticados do que os empreendedores de portfólio.

Já os empreendedores de portfólio manifestam de forma mais expressiva, que os seriais e noviços, a aspiração de estabelecer novos negócios. Também demonstram uma maior habilidade para identificar oportunidades de negócio.

Os empreendedores de portfólio, mais do que os outros tipos, demonstram não ter dificuldades para o levantamento de ideias para novos negócios. Entretanto, relatam que a dificuldade estaria na obtenção de recursos e capital para perseguir essas oportunidades.

Constata-se que ao propor tipos de empreendedores, os autores destacam características comuns a esses tipos. Santos (2008, p. 32) afirma "que recentemente a busca pelos traços ou características empreendedoras para promover a distinção entre empreendedores e nãoempreendedores obteve renovado interesse". Para esse autor, isso ocorre, tanto pela melhoria das técnicas metodológicas, como pela melhor definição de construtos e pela introdução de novas vertentes de análise.

Segundo Dolabela (1999) algumas características dos empreendedores aparecem em grande parte das pesquisas, 
mas isso também não garante que uma pessoa que as possua seja bem-sucedida em seu negócio, não permitindo estabelecer relação de causa-efeito. 0 que parece claro é que as chances do empreendedor diminuem bastante se não possui tais características.

Dornelas (2007) afirma que alguns aspectos referentes aos empreendedores como: iniciativa para criar um novo negócio e paixão pelo que faz; a utilização de recursos disponíveis de forma criativa, modificando o ambiente social e econômico onde está estabelecido, e também ao aceitar assumir riscos e a possibilidade de fracassar podem ser apontados em qualquer definição de empreendedorismo.

Drucker (2008, p. 33) afirma que "o espírito empreendedor é, portanto, uma característica distinta, seja de um indivíduo, ou de uma instituição". Enfatiza que o indivíduo que tenha que tomar uma decisão pode aprender a ser empreendedor e se comportar empreendedorialmente, ou seja, o empreendimento é um comportamento, e não um traço de personalidade.

Da mesma forma, Lezana e Tonelli (2004, p. 40) afirmam que, independentemente de região ou contexto sócio-econômico, os empreendedores possuem alguns comportamentos comuns. 0 que torna sua atuação diferenciada são suas características e o fato de ter uma empresa para satisfazer suas necessidades.

Gartner (1985; 1989) aborda as características empreendedoras, enfatizando o comportamento do empreendedor. Da mesma forma, o fazem Bygrave; Hofer (1991); Ucbasaran, Westhead, Wright (2001), Baron e Shane (2007), que em seus trabalhos passam a focar o empreendedorismo como processo.
Baron e Shane (2007) sugerem uma estrutura conceitual para entender o empreendedorismo como processo e apontam as suas fases. Para os autores, são as seguintes: 1) o reconhecimento de uma oportunidade; 2) a decisão de ir em frente e reunir os recursos iniciais; 3) o lançamento do novo negócio; 4) a construção do sucesso e, 5) a colheita das recompensas. Enfatizam que o processo é complexo e que não estipulam uma divisão em fases facilmente percebidas e demarcadas.

Sustentam que três tipos de variáveis influenciam todas as ações e decisões dos empreendedores e em todas as fases do processo empreendedor: são as variáveis de nível individual, as de nível grupal e as de nível social. As variáveis individuais são referentes às características do empreendedor, suas motivações e técnicas. As variáveis de nível global são informações de outras pessoas, ideias; a qualidade e a eficácia das relações com capitalistas, clientes, potenciais funcionários. Já as variáveis sociais envolvem políticas governamentais, tecnologia e condições econômicas (BARON; SHANE, 2007).

A fase inaugural refere-se ao reconhecimento de uma oportunidade e seria a identificação do potencial de criação de algo novo, como Schumpeter (1982) destaca. Um novo produto ou serviço, um novo mercado, um novo processo de produção, novas formas organizacionais das tecnologias são citadas por Baron e Shane (2007). Enfatizam que se trata de uma nova forma de combinação do que já existe.

A segunda fase trata da efetiva ação para ir em frente com a ideia ou a oportunidade. Uma coisa é decidir começar uma empresa; outra é realmente fazer. É necessário, para 
iniciar um negócio, reunir diversos tipos recursos: os humanos, os financeiros e as informações básicas sobre mercados, questões jurídicas e ambientais. Obter esses recursos é essencial e uma das fases mais difíceis do processo empreendedor.

A próxima fase é como uma consequência da segunda, pois é quando o novo negócio pode ser lançado. Aqui, trata-se de escolhas e ações práticas como formato jurídico, o desenvolvimento do novo produto ou serviço, a definição dos papéis da equipe dirigente.

A quarta fase envolve a administração do empreendimento e seu crescimento, com a obtenção de lucro. Nessa fase, é essencial considerar os recursos humanos, sobretudo como atrair e manter funcionários talentosos e motivados. Também demanda atenção à concepção de uma forte estratégia de negócios e a constante negociação com todos os envolvidos com a empresa, tanto interna como externamente.

A última fase refere-se a como os fundadores pretendem sair do negócio e colher as recompensas por seu trabalho. Afinal, empenharam-se, oferecendo seu tempo, talento e esforço. Basicamente, apresentam três opções: passar a empresa para pessoas próximas por meio da venda ou transferência; vender ou transferir para pessoas externas, ou abrir o capital.

Ao propor tal estrutura, esses autores referem-se ao desenvolvimento de atividades ao longo do tempo, em uma sequência organizada. Afirmam que dessa forma evita-se uma visão estática do empreendedorismo, que não é um ato acabado quando a empresa é lançada, bem como desperta atenção para as atividades que os empreendedores precisam realizar para transformar as ideias de novos serviços ou produtos em negócios de sucesso.

Com relação a essa última observação, Baron e Shane (2007, p. 15) destacam que "há muito reconhece-se que o desempenho dos empreendedores nessas atividades é, com frequência, mais importante para seu sucesso do que sua formação ou características pessoais" [....] e é "instrumento para identificar as habilidades, conhecimentos e características que os empreendedores possuem para desempenhar esse papel de forma eficaz".

Nesse sentido, o que já se sabe sobre o tema permite colaborar para com os empreendedores potenciais e os já em atividade na identificação do que precisa ser melhorado para aumentar as chances de sucesso. Para Drucker (2008, p. 45) "os empreendedores bem sucedidos, qualquer que seja a sua motivação pessoal - seja dinheiro, poder, curiosidade, ou desejo de fama ou reconhecimento -, tentam criar valor e fazer uma contribuição".

Nesse trabalho, adota-se o conceito de Lezana e Tonelli (2004, p. 39) para empreendedores que "podem ser definidos como indivíduos que inovam, identificam e criam oportunidades de negócios, montam e coordenam novas combinações de recursos (funções de produção), para extrair os melhores benefícios de suas inovações num meio incerto".

Esses empreendedores, quando possuidores de empreendimentos exitosos, procuram diversificar suas atividades, na mesma área de atuação ou em outra área, que conheça ou tenha interesse pessoal ou mesmo por hobby. Segundo Drucker (2008) os empreendedores querem mais; querem criar novos e diferentes valores, 
e também novas e diferentes satisfações, transformando material em recurso, ou combinando recursos existentes em uma nova e produtiva configuração. Para esse autor, é a mudança que irá proporcionar a oportunidade para o novo e o diferente.

Lezana e Tonelli $(2004$, p. 53) demonstram as principais características dos empreendedores de sucesso. As agrupam em quatro grupos de características: Necessidades, Conhecimentos, Habilidades e Valores, cada um deles compostos por algumas especificidades. Ressaltam que essas características podem atuar de forma positiva ou negativa.

Os mesmos autores baseiam-se em Birley e Westhead (1993) que adotam cinco tipos de necessidades, a partir de entrevistas com mais de 1000 empresários em onze países diferentes. São as necessidades de aprovação, independência, desenvolvimento pessoal, segurança e autorrealização.

Apontam um rol de conhecimentos necessários a quem estabelece um negócio e que são diferenciados a cada etapa em que a empresa esteja. Alguns, mais gerais, podem ser listados como aspectos técnicos relacionados com o negócio, experiência na área comercial, a escolaridade, a experiência em empresas, a formação complementar e a vivência com situações novas (LEZANA; TONELLI, 2004).

Apresentam também as habilidades que um empreendedor deve possuir ao iniciar seu empreendimento. Destacam que as facilidades para utilizar as capacidades físicas e intelectuais são muitas, mas destacam a identificação de novas oportunidades, a valoração de oportunidades e pensamento criativo, a comunicação persuasiva, a negociação, a aquisição de informações e a resolução de problemas. Segundo Tonelli (1997) vários estudiosos da área discutem as habilidades dos empreendedores. Cita o estudo de Ray (1993) que sintetiza as habilidades tratadas por outros autores.

Lezana e Tonelli (2004) descrevem os valores que definirão o que o empreendedor quer de seu negócio, com base em Empinott (1994). Afirmam que são esses valores que determinarão suas decisões pessoais e em relação à sociedade. Aponta valores existenciais, estéticos, intelectuais, morais e religiosos.

Nesse trabalho, o foco é conhecer de que tipo é e quais as características predominantes dos empreendedores de vinhos finos de altitude, no planalto catarinense. A tipologia utilizada é de Westhead e Wright (1998), descrita na parte inicial dessa seção.

A seção seguinte apresenta a atividade analisada e alguns de seus empreendedores, retratando-os quanto aos primeiros negócios e ingresso no segmento de vinhos de altitude.

\section{OS VINHOS DE ALTITUDE CATARINSENSE E SEUS EMPREENDEDORES}

Santa Catarina apresenta três regiões vitivinícolas definidas a partir de sua formação, a saber: a região denominada tradicional que ocupa duas áreas distintas no Estado, o Vale do Rio do Peixe, no MeioOeste (Videira, Tangará, Pinheiro Preto, Salto Veloso, Rio das Antas, Iomerê, Fraiburgo e Caçador) e a região Carbonífera no Sul do estado (Urussanga, Pedras Grandes, Braço do Norte, Nova Veneza e Morro da Fumaça).

A segunda área é denominada como a 
nova região, localizada nos municípios de Nova Trento, no vale do rio Tijucas, Rodeio no vale do rio Itajaí e Chapecó no Oeste. Rosier (2004) define o Planalto Serrano (São Joaquim, Bom Retiro e Urubici) como a terceira região, chamada de região supernova ou de altitude (ROSIER, 2004 apud BRDE, 2005).

Para Rosier (2004), em Santa Catarina, o desenvolvimento destes vinhedos nas localidades de Água Doce, Bom Retiro, Campos Novos, Iomerê, São Joaquim e Tangará, vem sendo acompanhado desde 1991 pelas equipes de pesquisa da Epagri das Estações Experimentais de Videira e de São Joaquim.

No Planalto Serrano Catarinense, para o mesmo autor, "a influência climática dada à altitude elevada, na latitude de $28^{\circ}$, proporciona um deslocamento de todo o ciclo produtivo da videira, a qual, em algumas variedades, inicia suas atividades vegetativas somente na segunda quinzena do mês de outubro e finaliza sua maturação também na segunda quinzena do mês de abril".

A expansão da vitivinicultura catarinense deve-se a uma série de fatores combinados. As pesquisas agropecuárias, com o desenvolvimento de cultivares e técnicas próprias para as condições de plantio e processamento nas diversas regiões do estado, como é o caso da UFSC e das Estações Experimentais da Epagri em Videira, Urussanga e São Joaquim (ALNOTÍCIAS, 2007).

0 evento considerado determinante para a atividade na região tem a ver com um experimento iniciado em 1991 com a plantação de uma coleção de nove variedades de uvas com três plantas cada, na Estação Experimental de São Joaquim. Esse experimento fazia parte de um projeto desenvolvido numa parceria entre a Estação Experimental de Videira, localizada no MeioOeste catarinense e o Conselho Nacional de Desenvolvimento Científico e Tecnológico (CNPq) para identificar as regiões do estado de Santa Catarina com maior aptidão para o cultivo da videira (NUNES JR. et al., 2009).

Os resultados obtidos com os primeiros vinhos elaborados no município demonstram o grande potencial da região para o cultivo de uvas viníferas. As características climáticas específicas do município são apontadas como diferencial na qualidade dos vinhos joaquinenses, pois a altitude em que se encontra cria uma condição climática diferenciada que permite a plena maturação das uvas, originando frutos com excelente qualidade para obtenção de vinhos, fato que vem surpreendendo os críticos (CORDEIRO, 2006).

Alguns empreendedores, como Wander Weege, Manoel Dilor de Freitas, José Eduardo Pioli Bassetti, Maurício Grando e Emílio Binotto acreditaram na atividade e realizaram investimentos, com a aquisição de terras, a implantação de vinhedos, e a montagem de vinícolas.

Manoel Dilor de Freitas tinha, entre seus negócios, a Cecrisa, empresa do ramo de revestimento cerâmico. Após completar 60 anos, começou a transferir a gestão de seus negócios para os filhos, procurando uma vida menos agitada. Para usufruir melhor sua família, adquiriu terras nos municípios catarinenses de Bom Retiro e, logo depois, em São Joaquim, de forma a usufruir todas as qualidades de um clima mais ameno e aconchegante. Em São Joaquim, passou 
a pesquisar sobre a produção de flores e frutas, algumas já cultivadas na região, como a maçã (ACAVITIS, 2009).

Em 1999, obteve informações junto a amigos e à Epagri, sobre a produção de uvas viníferas do tipo Cabernet Sauvignon. Descobriu as potencialidades locais e a possibilidade de produzirem-se vinhos com valor agregado, de alta qualidade. Já em 2001, foi realizado o primeiro investimento no projeto, após detalhado estudo técnico sobre o potencial do negócio na Região, estava criada a Villa Francioni.

A partir daí, Freitas buscou informações e experiências nos melhores centros de produção, com visitas a vinícolas e vinhedos na França, na Itália, no Chile e na Argentina. Também visitou a Califórnia, ao final de seu percurso, acompanhado por dois especialistas em Enologia e Agronomia.

Em 2003, a vinícola estava em construção e os filhos participavam das reuniões técnicas e recebiam informações sobre o projeto. Nesse período, a família inteira realizou uma viagem de 10 dias pelos principais pólos produtores da França para conhecer vinícolas e aprender as particularidades do mundo do vinho. Após duas semanas do retorno ao Brasil, Freitas faleceu. Os filhos deram sequência ao empreendimento, sendo inaugurada a vinícola Villa Francioni em dezembro de 2005.

Alguns vinhos produzidos por essa vinícola foram premiados em concursos nacionais, sendo a vinícola considerada referência entre os vinhos brasileiros, segundo Rigon (2008). Alguns prêmios conquistados foram o Villa Francioni Tinto 2004, eleito o melhor vinho tinto nacional de 2007, pela Confraria dos Sommeliers de São Paulo e Rio de Janeiro; para o Villa Francioni Chardonnay 2006, eleito o melhor Chardonnay no Prêmio Top-10 da Expovinis 2007 e também, a própria Villa Francioni foi eleita Vinícola do ano 2006 pela Associação Brasileira de Sommeliers de São Paulo.

Wander Weege, herdeiro e administrador das Malhas Malwee, é outro empreendedor em vinhos de altitude. Apaixonado por vinhos, e integrante do Clube do Vinho, em Blumenau, e do Clube dos Gourmets de Florianópolis, conheceu São Joaquim e lá adquiriu terras e a Fazenda Menino Deus, na localidade chamada Pericó, no final de 2002. 0 projeto da Vinícola Pericó iniciou-se em fevereiro de 2003, com assessoria externa.

Wander Weege, juntamente com Laurita Karsten Weege, desde 1985, administra a empresa Malwee Malhas. Wander participava do Clube do Vinho de Blumenau e conheceu São Joaquim, que seria local adequado para a produção de uvas e vinhos. 0 que o motivou a investir na atividade vinícola foi o desafio de produzir uvas e vinhos de qualidade em Santa Catarina, nas terras de altitude, em São Joaquim. Para tanto, adquiriu a Fazenda Menino Deus, Distrito do Pericó, no final de 2002, e a primeira safra foi em 2007, com a produção do vinho Taipa rosé-seco.

A Vinícola Pericó está instalada em 15 hectares, a 1300 metros de altitude, no vale do Pericó, e cultiva uvas Cabernet Sauvignon, Merlot e Pinot Noir, sendo que os pés de uva são importados da França. A produção dos vinhos é terceirizada para as Vinícolas Monte Reale e Fabian. Produziu o primeiro espumante das terras de altitude catarinenses. 0 projeto da vinícola própria está pronto.

O espumante Cave Pericó Brut Rose 
2008 conquistou a medalha de ouro no VI Concurso Espumante Brasileiro, promovido pela Associação Brasileira de Enologia (ABE). Esse concurso ocorreu em GaribaldiRS, em agosto de 2009, com a participação de 65 profissionais de diversos estados brasileiros, entre enólogos, jornalistas e experts.

Outro empresário que investiu em videiras e produção de vinhos foi José Eduardo Pioli Bassetti, que até 2009 era proprietário da editora Aventura Brasileira, com sede em Florianópolis. Juntamente com seus dois irmãos, Marco Aurélio e César Juliano, investiram cerca de R\$600 mil para iniciar, em 2005, o plantio de uvas tipo Merlot e Cabernet Sauvignon, com intenção de elaborar vinhos.

Nos dois anos seguintes, empenharam-se na proteção às plantações contra o granizo, que pode atingir as videiras. Também pretendem construir uma cantina. "Mesmo se não desse lucro, era um investimento que eu faria”, observa Pioli Bassetti, citando o prazer da atividade para quem é enófilo.

A família de Emílio Binotto, da transportadora Binotto e Vinícola Santo Emílio; e Maurício Grando, da Vinícola Villaggio Grando também são exemplos de empreendedores de vinhos de altitude. Esses homens e mulheres de negócios estão ampliando as áreas de produção de uvas viníferas e de vinhos. A paixão pela atividade os move, mas também, a perspectiva de bons resultados nesses novos negócios.

0 grupo empresarial Binotto, de Lages, também investiu na produção de vinhos finos de altitude na Serra Catarinense. A Binotto SA é uma das seis maiores transportadoras do Brasil e, em 2003, essa família adquiriu a Fazenda Quinta dos Montes, situada em Urupema, em um dos pontos mais altos e frios do Brasil, oferecendo um terroir propício ao cultivo de uvas de alta qualidade.

Em 2004, foram plantados 15 hectares de uvas Cabernet Sauvignon e Merlot, sendo que a primeira safra, em 2006, permitiu a elaboração de 5000 litros de vinhos, não sendo comercializados, somente utilizados para degustação. Já em 2007 foram 20.000 litros e, em 2008, 30.000 litros.

A empresária Elizabeth Binotto Bazzo, filha do fundador e diretora administrativa e financeira da Binotto, é a responsável pela iniciativa. 0 fundador Emílio Binotto foi homenageado com o nome da vinícola. 0 projeto iniciou-se com pesquisa para o plantio de uvas e a futura produção de vinhos. Segundo Elizabeth Binotto, tratavase de hobby, ao se iniciar a atividade, mas ao alcançar resultados positivos, decidiram investir no novo negócio.

Cercaram-se de expertises e tiveram contato com as referências no mercado internacional na produção de vinhos de classe mundial. Após dois anos de análises, estudos e pesquisas, estava constituída a Vinícola Santo Emílio, produzindo vinhos finos. 0 vinho tinto Leopoldo foi lançado nacionalmente em 2008, na Expovinis, e também, o espumante Stellato Rose Brut, no ano 2009.

A vinícola pretende plantar 40 hectares, nos próximos 5 anos, para a produção de espumantes e vinhos tintos e brancos. Também está prevista a construção de uma vinícola na própria fazenda e o incremento do enoturismo na serra catarinense.

Outro empresário do ramo de madeiras investiu em vinhos de altitude. Maurício Grando, de Caçador, é sócio-fundador das 
empresas Madepinus Indústria e Comércio, Salto Grande Poupa Madeiras Ltda e da GBM Agroflorestal Ltda.

O empresário Maurício Grando conta que quem lhe chamou a atenção para a potencialidade de suas terras para o cultivo de uvas viníferas foi o empresário francês Jean Luc Drouhin, cuja família produz vinhos há 200 anos na região de Bordeaux. Isso foi em 1998 e Grando conta que precisou de um ano para se convencer de que podia plantar uvas viníferas com bom resultado em suas terras.

A partir de um encontro com o enólogo Jean Pierre Rosier, formado em Bordeaux, na França, teve início o projeto de uma grande e moderna vinícola de qualidade superior. A vinícola Villagio Grando localiza-se em Bosque de Araucárias em Herciliópolis-SC e possui um terroir diferenciado e excepcional para elaboração de vinhos.

Na edição da Expovinis 2010, a Villagio Grando, do município de Água Doce (Caçador), recebeu prêmio TOP TEN como melhor vinho Chardonay da feira, safra 2008.

\section{ANÁLISE E CLASSIFICAÇÃO DOS EMPREENDEDORES DE VINHOS DE ALTITUDE}

Considerando a tipologia de Westhead e Wright (1998), os empreendedores de vinhos de altitude são do tipo portfólio, pois para os casos pesquisados, os negócios de vinho desenvolvidos ocorreram paralelamente às atividades previamente existentes. Ao considerá-los desse tipo e analisar as informações e dados obtidos na pesquisa de campo para verificar quais características utilizaram, constatase que são as habilidades. Ray (1993) as descreve como sendo a identificação de novas oportunidades, a valoração de oportunidades e pensamento criativo, a comunicação persuasiva, a negociação, a aquisição de informações e a resolução de problemas.

Segundo Lezana e Tonelli (2004) a identificação de novas oportunidades é uma habilidade característica do empreendedor e tem a ver com a capacidade de enxergar o que os outros não estão vendo. Depende da criatividade e do pensamento inovador. Quem está à frente da empresa não pode perder contato com a realidade que o cerca. Esta é uma habilidade muito útil já que permite descobrir produtos e serviços, utilizar e incorporar novas tecnologias (BARON; SHANE, 2007; UCBASARAN; WESTHEAD; WRIGHT, 2001).

A valoração de oportunidades e pensamento criativo tem a ver com a separação de uma oportunidade falsa, de uma oportunidade real. 0 empreendedor tem que pensar criativamente. Não basta enxergar a oportunidade, tem que valorá-la, atribuir um valor.

O início de um negócio começa com uma ideia e, para concretizar esta ideia, o empreendedor tem que convencer as pessoas a se agregarem ao negócio, seja fornecedores, amigos, família, clientes ou bancos. Compreende a comunicação oral e a escrita (LEZANA; TONELLI, 2004).

A habilidade de negociar é desenvolvida, sobretudo, pela experiência, e envolve outras características de personalidade. Abrangem fornecedores, clientes e outros parceiros da empresa, em que cada um defende seu interesse, assim como o empreendedor o faz.

A aquisição de informações permite flexibilidade e um diferencial à empresa, pois permite ao empreendedor atender 
as exigências do mercado, produzindo com mais qualidade, menor preço e maior garantia. Da mesma forma, é a capacidade de resolver problemas, seja de forma inovadora ou adaptativa. Cada problema exigirá uma solução específica e, em alguns casos, não dependerá somente do empreendedor.

Todos os empreendedores pesquisados são oriundos de outras atividades produtivas, sendo que, basicamente, foram os negócios anteriores que financiaram o novo empreendimento. Possuem habilidades como a capacidade de identificação de novas oportunidades. Dillor, Weege, Bassetti, Grando e Binotto, sendo empreendedores de portfólio, buscaram a maior quantidade de fonte de informação possível para estabelecer o negócio. E as redes e relacionamentos sociais anteriores construídos, bem como suas experiências de negócios, ajudaram no levantamento de informações, outra habilidade que utilizam.

Da mesma forma, valorizaram a oportunidade e realizaram investimentos, agregando os recursos necessários como os financeiros, humanos e de mercado. Contrataram enólogos, técnicos e funcionários capacitados; contataram entidades e organismos de pesquisa e de fomento, exercendo outra habilidade que é a de negociação. Ao constituir a ACAVITIS, esses empreendedores articularam-se para defender seus interesses, o que pressupõe a habilidade de comunicação persuasiva.

Esses empreendedores constituíram novo empreendimento, ao utilizar suas habilidades, já anteriormente exercidas em negócios anteriores. No caso analisado, foram apresentados 5 empreendedores de vinhos de altitude, associados da ACAVITIS, de um total de 28, aproximadamente.

\section{CONSIDERAÇÕES FINAIS}

Esse estudo revela uma evidência de um tipo específico de empreendedor atuando no estado de Santa Catarina e na atividade analisada, e que pesquisas mais aprofundadas poderiam contribuir para que autoridades e agentes de desenvolvimento e fomento elaborassem instrumentos e medidas de forma a alavancar esse potencial de crescimento.

Empreendedores de portfólio utilizam suas habilidades para a construção e consolidação de seus negócios. Considerando o que a literatura retrata, o processo empreendedor é bastante dinâmico e exige o desempenho de variadas atividades de seus empreendedores, o que permite identificar as habilidades e características que possuem.

Nas pesquisas e entrevistas realizadas sobressai a paixão por vinho, o reconhecimento e valorização da oportunidade, a busca de informações, a comunicação, a contratação de pessoal especializado, a evolução da atividade, principalmente, após a constituição da ACAVITIS e a busca da construção de uma marca coletiva, com o apoio de entidades como o SEBRAE, a EPAGRI e a EMBRAPA UVA E VINHO.

Pesquisas com maiores amostras e focando outros setores da economia são recomendadas para um melhor entendimento da abrangência do fenômeno. Assim como, estudos longitudinais poderiam permitir um melhor acompanhamento da geração de riqueza e desenvolvimento local proporcionado por cada tipo de empreendedor. 


\section{REFERÊNCIAS}

ACAVITIS. Associação Catarinense dos Produtores de Vinhos Finos de Altitude. 2009. Disponível em <http://www. acavitis.com.br/> Acessos em 01 set. 2011.

AL NOTíCIAS: Jornal da Assembléia Legislativa de Santa Catarina. A riqueza brota da uva. Florianópolis, p. 1-8. 13 jul. 2007. Disponível em: <http://ww1.alesc.sc.gov.br/portal/jornalAlNoticia/jornal_pdf/julho/ed263.pdf>. Acesso em: 20 set. 2009

ARDICHVILI, A.; CARDOZO, R.; RAY, S. A theory of entrepreneurial opportunity identification and development. Journal of Business Venturing, v. 18, p. 105-123, 2003.

BANCO REGIONAL DE DESENVOLVIMENTO DO EXTREMO SUL. Vitivinicultura em Santa Catarina: situação atual e perspectivas. Florianópolis, BRDE, 2005.

BARON, R.A.; SHANE, S.A. Empreendedorismo: uma visão do processo. São Paulo: Thomson Learning, 2007.

BIRLEY, S.; WESTHEAD, P. A Comparison of new businesses established by "novice" and "habitual"founders in Great Britain. International Small Business Journal, v.12 p. 38-60, 1993.

BROLLO, M. X. Intenções empreendedoras: um modelo econômico-psicológico entre estudantes universitários. 2006. Tese (Doutorado em Engenharia de Produção) - Universidade Federal de Santa Catarina, Florianópolis, 2006.

BYGRAVE, W. D.; HOFER, C.W. Theorizing about entrepreneurship. Entrepreneurship Theory and Pratice. V.16, n. 2, p. 13-22, Winter, 1991.

COLLIS, J.; HUSSEY, R. Pesquisa em administração: um guia prático para alunos de graduação e pós-graduação. 2.ed. Porto Alegre: Bookman, 2005.

CORDEIRO, W. C. A vitivinicultura em São Joaquim - SC: uma nova atividade no município Wilton Carlos Cordeiro - Florianópolis, 2006.

DIEHL, A. A.; TATIM, D.C. Pesquisa em ciências sociais aplicadas: métodos e técnicas. São Paulo: Prentice Hall, 2004.

DOLABELA, F. Oficina do Empreendedor. São Paulo: Cultura Editores, 1999.

DORNELLAS, J. C. Empreendedorismo na prática. Mitos e verdades do empreendedor de sucesso. Rio de Janeiro: Elsevier, 2007.

DRUCKER, P.F. Inovação e espírito empreendedor: prática e princípios. São Paulo: Pioneira, 2008.

EMPINOTTI, M. C. Os valores a serviço da pessoa humana. Porto Alegre: EDIPUCRS, 1994.

GARTNER, W.D. Who is a entrepreneur? Is the wrong question. Entrepreneurship Theory and Pratice. V.13, n. 4, p. 47-68, Summer, 1989.

GARTNER, W.D.; SHANE, S. Measuring entrepreneurship over time. Journal of Business Venturing, v. 10, n. 4, p.283-301, Spring, 1995.

HYYTINEN , A.;ILMAKUNNAS, P. What distinguishes a serial entrepreneur? Industrial and Corporate Change. V.16, n.5, p. 793-821, 2007.

LEZANA, Á. G. R.; TONELLI, A. O comportamento do empreendedor. In: DE MORI, F.(Org). Empreender. Florianópolis: Escola de Novos Empreendedores. 2004.

NUNES JR., C. L.; FERREIRA, N. A. C.; MINUZZI, J.; CASAROTTO FILHO, N. Analise do APL de Vinhos de Altitude do Planalto Catarinense. In: ENCONTRO DE ESTUDOS SOBRE EMPREENDEDORISMO E GESTÃO DE PEQUENAS EMPRESAS (EGEPE), 6., 2009, Recife-PE. Anais... Recife, 2009. 1 CD.

RAY, D.M. Understanding the entrepreneur: attributes, experiences and skills. Entrepreneurship and Regional Development. v.5, p. 345-357. 1993.

ROSIER, J. P. Novas regiões: vinhos de altitude no sul do Brasil. In: CONGRESSO BRASILEIRO DE VITICULTURA E ENOLOGIA, 10., 2004. Anais... 1 CD. 
SANTOS, P. C. F. Uma escala para identificar potencial empreendedor. 2008. Tese (Doutorado em Engenharia de Produção) - Universidade Federal de Santa Catarina, Florianópolis, 2008.

SCHUMPETER J. A. Teoria do desenvolvimento econômico. São Paulo: Abril Cultural.1982.

TONELLI, Alessandra. Elaboração de uma metodologia de capacitação aplicada ao estudo das características comportamentais dos empreendedores. Florianópolis, 1997. Dissertação (Mestrado em Engenharia de Produção) - Universidade Federal de Santa Catarina, Florianópolis, 1997.

UCBASARAN,D.; WESTHEAD,P;; WRIGHT, M. The focus of entrepreneurial research: contextual and process issues. Entrepreneurship Theory and Pratice, v.25, n. 5, p. 57-80, Summer, 2001.

WESTHEAD, P.; BIRLEY, S. Environments for business deregistrations in the United Kingdom, 1987-1990. Entrepreurship and Regional Development. v. 6, p. 29-62.1994.

WESTHEAD, P.; WRIGHT, M. Novice, portfolio, and serial founders: are they different? Journal of Business Venturing, v.13, n. 3, p. 173-204, 1998.

WESTHEAD, P.; UCBASARAN, D.; WRIGHT, M. Decisions, Actions, and Performance: Do Novice, Serial, and Portfolio Entrepreneurs Differ? Journal of Small Business Management, v. 43, n. 4, p.393-417, 2005

\section{Nubia Alves de Carvalho Ferreira}

Administradora e economista, doutoranda do Programa de Pós-graduação em Engenharia de Produção (PPGEP) da Universidade Federal de Santa Catarina (UFSC)

Endereço eletrônico: nubia@deps.ufsc.br

Lattes - http://buscatextual.cnpq.br/buscatextual/visualizacv.do?id=K4779298T0

\section{Carlos Luiz Nunes Júnior}

Administrador, mestrando do Programa de Pós-graduação em Engenharia de Produção (PPGEP) da Universidade Federal de Santa Catarina (UFSC)

Endereço eletrônico: jrnunes1111@gmail.com

Lattes- http://buscatextual.cnpq.br/buscatextual/visualizacv.do?id=K4484682P7

\section{Álvaro Guillermo Rojas Lezana}

Professor Doutor do Programa de Pós-graduação em Engenharia de Produção (PPGEP) da Universidade Federal de Santa Catarina (UFSC).

Endereço eletrônico: lezana@deps.ufsc.br

Lattes - http://buscatextual.cnpq.br/buscatextual/visualizacv.do?id=K4780380A2 
